\title{
THE DERIVATIVE ASPECT OF THE FORMATION OF THE PREFIXAL AND ONOMASIOLOGICAL CATEGORY OF NEGATION
}

\author{
Olga MIGORIAN \\ Yuriy Fedkovych Chernivtsi National University, Chernivtsi, Ukraine
}

\begin{abstract}
The article addresses the formation of the prefixal and onomasiological category of Negation in Old English, Middle English, Early New English and New English. The work represents basic lexico-semantic groups of verb and noun bases, which actively participate in the formation of the onomasiological category of Negation across different periods in the history of the English. It includes a complex diachronical study of the English prefixal derivatives from the point of view of their word-formation potential within the onomasiological category of Negation. It presents an analysis of the considerable changes in the semantic and onomasiological structures within the frame of the onomasiological category of Negation in the history of the English language.
\end{abstract}

Keywords: verbal and substantive derivative basis, negation category, onomasiology, prefixation, word-formation, diachrony

\section{Introduction}

The study of word-formation processes, which resulted in the genesis of the current system of language derivative units and changes that have been subjected to its separate parts since their inception, is among the topical issues of modern theoretical linguistics. The focus of this type of research should be the formation problems of structural, semantic and onomasiological structures within the same derivative word, one and the same word-building model. The idea of this approach is to show if the new act of word-formation is always a reflection of the past acts of nomination, and if so, what the nature of such a certainty is [Kizyukevich 47-55]. The question of the diversity, specificity and onomasiological boundaries of word formation, of morphological phenomena which accompany the process of derivation and influence its "tactical" 
capabilities, is elaborated in the literature [Zemskaya 2004; Lopatin 1974; Kubryakova 2008; Poluzhin 1992; Selivanova 2008; Ulukhanov 1980]. However, we still do not have an integral and consistent perception that would represent the dynamics of those derivative and onomasiological mechanisms that led to the formation of the current system of prefixal-onomasiological category of Negation. Therefore, there is an urgent need for an in-depth study of the multidirectional evolutionary changes associated with the formation and further development of the totality of nominative processes that took place in the history of the development of this category. The combination of diachronic and synchronic approaches in the English prefixal derivatives study will give us the possibility not only to generalize the categorization regularities of environmental phenomena, but also to single out and explain the formation of the system of phenomena that are specific to the onomasiological category of Negation. Environmental phenomena were grouped according to their meanings into the lexicosemantic groups to make a more convenient mechanism of category formation with the help of prefixal units.

The objective of the article is to explore in detail the derivative aspect of the formation of the prefixal and onomasiological category of negation in the evolution of the English language. This objective requires the completion of the following tasks:

- to single out lexical and semantic groups (hereinafter - LSG) of derivative bases taking part in the formation of the prefixal and onomasiological category of Negation;

- to observe the notional peculiarities of the compatibility between verbal and substantive bases LSG and prefixes of the onomasiological category of Negation;

- to compare the derivative peculiarities in the formation of the prefixal and onomasiological category of Negation arising from the verbal, substantive and, within them, the lexical and semantic origin of derivative bases studied as components of derivatives.

\section{Discussion: Structural and Semantic Patterns of the Onomasiological Category of Negation}

The object of the investigation is 11000 prefixal derivatives, of which 2789 lexical units represent the onomasiological category of Negation during the four stages in the history of English. The topic of the article is the structural, semantic and nominative peculiarities of the verbal and substantive prefixal derivatives which take part in the formation of the prefixal and onomasiological category of Negation during all the lexicalized periods of the English language history.

The onomasiological functions of derivative words are related primarily to the investigation of the conversion of the knowledge about natural phenomena 
into the content transmitted by the dissected structure of the verbal nominative mark. Here is the definition proposed by O. Selivanova: "the onomasiological structure of prefixal derivatives consists of the onomasiological basis, indicating a conceptual class, generic notion, and of the onomasiological sign, indicating the specific differences that distinguish the object within the class" [Selivanova 153]. Negation in linguistic literature is assumed as the expression through various linguistic devices of the state of things when the relationship between the elements of expression is perceived as unreal or nonexistent at some point [Polyuzhyn 30], and also the onomasiological basis, which is formed by the derivative bases of these derivatives. To determine the conceptual class of the onomasiological basis, we have singled out lexical-grammatical and lexicalsemantic groups of the derivative bases.

We have singled out 9 LSG of verbal derivative bases: 1) verbs of phase $\left(\mathbf{V}_{\mathbf{1}}\right)$; 2) verbs of motion $\left(\mathbf{V}_{\mathbf{2}}\right)$; 3) verbs of presence $\left(\mathbf{V}_{\mathbf{3}}\right)$; 4) verbs of location $\left(\mathbf{V}_{4}\right)$; 5) verbs of being $\left(\mathbf{V}_{\mathbf{5}}\right)$; 6) verbs of feelings $\left(\mathbf{V}_{\mathbf{6}}\right)$; 7) verbs of intellectual activity $\left(\mathbf{V}_{\mathbf{7}}\right)$; 8) verbs of physical activity $\left(\mathbf{V}_{\mathbf{8}}\right)$; 9) verbs of communication $\left(\mathbf{V}_{\mathbf{9}}\right)$ and 19 LSG of substantive derivative bases: $\mathbf{N}_{1}$.environment and geography, $\mathbf{N}_{2}$.weather and natural calamity, $\mathbf{N}_{3}$.geometry and size, $\mathbf{N}_{4}$.time, $\mathbf{N}_{5}$.subjects and substance, $\mathbf{N}_{6}$. representatives of plants and animals, $\mathbf{N}_{7}$.human being, $\mathbf{N}_{8}$.houses and buildings, $\mathbf{N}_{\mathbf{9}}$.clothes, $\mathbf{N}_{\mathbf{1 0}}$.nourishment, $\mathbf{N}_{\mathbf{1 1}}$.emotions, $\mathbf{N}_{\mathbf{1 2}}$. intellect, $\mathbf{N}_{13}$.culture and science, $\mathbf{N}_{14 . a c t i o n s,} \mathbf{N}_{15}$.movement and transport,

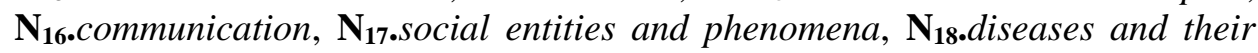
treatment, $\mathbf{N}_{\mathbf{1 9}}$.physical state.

The largest number of LSG of the productive substantive bases are involved in the formation of the onomasiological category of Negation (OCN) all 19 of investigated units. However, such a representation of the OCN was not a characteristic of the first two periods in the history of the English language. In Old English, it was represented by only five LSG with the notions of: "human being"; "emotions"; "intellect"; "actions"; "communication". In Middle English their inventory grew by nine LSG: "geometry and sizes"; "time"; " representatives of plants and animals "; "clothes"; " nourishment"; "culture and science"; " social entities and phenomena"; " diseases and their treatment "; "physical state”; in Early New English - " environment and geography"; " weather and natural calamity"; " subjects and substance"; " houses and buildings"; " movement and transport".

During the four periods in the history of the English language, the value of the category of Negation is acquired by a small number of LSG of verbal derivative bases that reflect the phenomena of the world: LSG with "motion" and "physical activity". We also discovered LSG of verbal derivative bases that emphasized negation during one or two stages in the history of English: LSG with reference to "communication" - in Old English and Early New English, 
LSG with reference to "location", "intellectual activity", "feelings" - in Middle English.

The nucleus, the main structure, and the periphery of the onomasiological category of Negation for each historical period were joined by new components. The main structure during the Old English period consisted of the following LSG: $\mathbf{N}_{\mathbf{1 1}}, \mathbf{N}_{\mathbf{1 2}}, \mathbf{N}_{\mathbf{1 6}}$, in Middle English, LSG $\mathbf{N}_{\mathbf{7}}$ and $\mathbf{N}_{\mathbf{1 4}}$ were added along with $\mathbf{N}_{17}$ and $\mathbf{N}_{19}$ from the periphery, which came into use in this onomasiological category. In Early New English, $\mathbf{N}_{\mathbf{9}}, \mathbf{N}_{\mathbf{1 3}}$ from the periphery, and $\mathbf{N}_{1}, \mathbf{N}_{\mathbf{2}}, \mathbf{N}_{\mathbf{5}}, \mathbf{N}_{15}$ were added, the prefixal derivatives of which began to form the onomasiological category of Negation. The nucleus of this category in Old English was $\mathbf{N}_{\mathbf{1 1}}$ and $\mathbf{N}_{\mathbf{1 6}}$, in Middle English it expanded with the help of $\mathbf{N}_{\mathbf{1 2}}$ from the main structure, in Early New English $-\mathbf{N}_{\mathbf{7}}, \mathbf{N}_{\mathbf{1 4}}, \mathbf{N}_{\mathbf{1 7}}$, also from the main structure. The periphery was formed in Old English with the participation of $\mathbf{N}_{7}$ and $\mathbf{N}_{\mathbf{1 4}}$, in Middle English they were displaced into the main structure: $\mathbf{N}_{\mathbf{3}}, \mathbf{N}_{\mathbf{4}}$, $\mathbf{N}_{\mathbf{6}}, \mathbf{N}_{\mathbf{9}}, \mathbf{N}_{\mathbf{1 0}}, \mathbf{N}_{\mathbf{1 3}}, \mathbf{N}_{\mathbf{1 8}}$ and in Early New English it was supplemented with $\mathbf{N}_{\mathbf{8}}$.

Structurally-semantic models, which are idiomatic for the onomasiological category of Negation, remained more or less productive throughout the history of English. For example, $\mathrm{Pr}+\mathrm{N} \rightarrow \mathrm{D}$ is productive; $\mathrm{Pr}+$ $\mathrm{N}_{1} \rightarrow \mathrm{D}, \mathrm{Pr}+\mathrm{N}_{2} \rightarrow \mathrm{D}, \mathrm{Pr}+\mathrm{N}_{3} \rightarrow \mathrm{D}, \mathrm{Pr}+\mathrm{N}_{4} \rightarrow \mathrm{D}, \mathrm{Pr}+\mathrm{N}_{5} \rightarrow \mathrm{D}, \mathrm{Pr}+\mathrm{N}_{6} \rightarrow \mathrm{D}$, $\mathrm{Pr}+\mathrm{N}_{8} \rightarrow \mathrm{D}, \operatorname{Pr}+\mathrm{N}_{9} \rightarrow \mathrm{D}, \operatorname{Pr}+\mathrm{N}_{10} \rightarrow \mathrm{D}, \mathrm{Pr}+\mathrm{N}_{13} \rightarrow \mathrm{D}, \mathrm{Pr}+\mathrm{N}_{15} \rightarrow \mathrm{D}, \mathrm{Pr}+$ $\mathrm{N}_{18} \rightarrow \mathrm{D}, \mathrm{Pr}+\mathrm{N}_{19} \rightarrow \mathrm{D}$ - non-productive, $\mathrm{Pr}+\mathrm{N}_{12} \rightarrow \mathrm{D}, \mathrm{Pr}+\mathrm{N}_{16} \rightarrow \mathrm{D}$ are models that already became productive in Middle English, and $\mathrm{Pr}+\mathrm{N}_{7} \rightarrow \mathrm{D}, \mathrm{Pr}$ $+\mathrm{N}_{14} \rightarrow \mathrm{D}, \mathrm{Pr}+\mathrm{N}_{15} \rightarrow \mathrm{D}$ already became productive in Early New English. Let us consider the main characteristics that appear in LSG during the formation of the onomasiological category of Negation. To do this, we will study the compatibility dynamics of the LSG of the onomasiological category of Negation with its prefixes.

In the formation of the onomasiological category of Negation, the following basic LSG are involved: $\mathrm{N}_{11}, \mathrm{~N}_{12}, \mathrm{~N}_{16}$. The semantic potential of LSG $\mathrm{N}_{11}$ of this category was implemented in ascending order during the four periods of the history of English. So, in Old English, it was combined with prefixes: med-, or-, un-, wan-. A significant number of prefixes of LSG $\mathrm{N}_{11}$, which is half of the current prefixal inventory of the onomasiological category of Negation, were used in Middle English. These are: dis-, mis-, non-, at the same time derivatives of this onomasiological category, formed with the participation of med-, ceased to be formed. In Early New English, the category set of prefixes changed because derivatives formed with the use of authentic prefixes: non-, or-, un-, wan-, were by now out of use. These prefixes were replaced by: $a-$, semi-, that participate in the formation of quite a large number of new lexical units. For example, or-treowness (trust) - o.e. distrust.

In Old English LSG $\mathrm{N}_{12}$ was combined with the prefix un-, which continues to participate in the formation of derivatives up to the New English 
period. In Middle English, this group began to combine with the prefixes: dis-, in-, non-, the derivatives of which still exist, and prefixes: over-, on-, re-. But derivatives, formed with the last three mentioned prefixes, were out of use in Early New English. The modern inventory of LSG N ${ }_{12}$ prefixes of this category, was formed mainly in Middle English and Early New English, where it began to join prefixes: mis-, non-, under-. For example, un-gewittigness (mind) - o.e. madness.

The intense activity of LSG $\mathrm{N}_{16}$ was manifest in Middle English due to its combinations with the prefixes: dis-, ex-, in- and also mis-, or-, un-, which began to participate in the formation of Negation in Old English. In Early New English, the prefix inventory of the mentioned LSG grew at the expense of such units as: $a b-, n o n-$, under-. At the same time, the prefixes $o r$ - and $u n-$ went out of use. For example, dis-board - n.e. to disembark.

The category of Negation is also characterized by LSG, the wordbuilding potential of which expanded with the new additions: $\mathrm{N}_{7}, \mathrm{~N}_{13}, \mathrm{~N}_{14}, \mathrm{~N}_{17}$, and $\mathrm{N}_{19}$. LSG $\mathrm{N}_{7}$ and $\mathrm{N}_{14}$ formed the onomasiological category of Negation since Old English and underwent a significant expansion of their word-building potential in Early English. So, LSG $\mathrm{N}_{7}$ in Early New English combined with most of the inventory of prefixes that are involved in the formation of this category: anti-, be-, ex-, non-, semi-, under-. They joined the word-formation models of this LSG, formed with the help of Negation prefixes, which constitute a peculiar "foundation" of this category in combination with LSG $\mathrm{N}_{7}$, as they are involved in its formation during the four periods of the history of English. They are: un- from Old English and dis- from Middle English. During the formation of the onomasiological category of Negation, LSG $\mathrm{N}_{7}$ also combined with prefixes that ceased to form derivatives in Middle English: wan-; and in Early New English: de-, non-, but their output did not significantly affect its development. For example, wan + bode (messenger) - o.e. who bids a low price.

The main extension of LSG $\mathrm{N}_{14}$ of the onomasiological category of Negation was in Early New English, as the current inventory of prefixes of this category consists of the prefixes: ex-, semi-, and under-, which began to give the meaning of negation to $\mathrm{N}_{14}$ in Early New English, and the basic prefixes which are those which have participated in the formation of the onomasiological category of Negation for the last three historical periods: in-, non-. The number of prefixes that ceased to form derivatives of the onomasiological category of Negation are not significant (2 lexical units). They are dis- in Middle English and $u n$ - in Early New English. This fact, however, did not prevent the wordbuilding potential of LSG $\mathrm{N}_{14}$ from realizing from its significant expansion during the formation of the onomasiological category of Negation. For example, non-packing - m.e. unpacking.

LSG $\mathrm{N}_{13}, \mathrm{~N}_{17}, \mathrm{~N}_{19}$ have formed the onomasiological category of Negation since Middle English but the significant realization of their word- 
building potential occured in th Early New English. So, LSG $\mathrm{N}_{13}$ combined with the prefix in- in Middle English, and in Early New English its inventory grew at the expense of such prefixes as: $a-$, apo-, extra-, non-, semi-. For example, irreligiosite (religiosity) - m.e. irreligiousness.

LSG $\mathrm{N}_{17}$ came into Middle English with prefixes: de-, mis-, non-, and in Early New English the prefix mis- was forced out by the prefix under-. For example, mis-order - m.e. absence or breach of order. Two prefixes of LSG $\mathrm{N}_{19}$, which represent half of its modern prefixal inventory, came into use in Early New English. They are: non- and under-. Among other prefixes of LSG $\mathrm{N}_{19}$ we focused on un-, since its derivatives are found only in Old English, as well as on the borrowed prefix in- in Middle English, which together with LSG $\mathrm{N}_{19}$ continues to participate in the formation of the onomasiological category of Negation. For example, non-being - e.n.e. the condition of not being, nonexistence.

Among LSG of the onomasiological category of Negation, the wordbuilding potential of which is realized insignificantly or not at all, we found: $\mathrm{N}_{1}$, $\mathrm{N}_{2}, \mathrm{~N}_{3}, \mathrm{~N}_{4}, \mathrm{~N}_{5}, \mathrm{~N}_{6}, \mathrm{~N}_{8}, \mathrm{~N}_{9}, \mathrm{~N}_{10}, \mathrm{~N}_{15}, \mathrm{~N}_{18}$. These LSG began to form the onomasiological category of Negation since Middle English or Early New English.

LSG $\mathrm{N}_{3}, \mathrm{~N}_{4}, \mathrm{~N}_{6}, \mathrm{~N}_{9}, \mathrm{~N}_{10}, \mathrm{~N}_{18}$ have been involved in the formation of the onomasiological category of Negation since Middle English. So, LSG $\mathrm{N}_{3}$ of Middle English was combined with the prefixes: in- and $u n$-, which in Early New English were forced out by the prefix under-. For example, im-propotionm.e. want of proportion, disproportion.

LSG $\mathrm{N}_{4}$ began to combine with the prefix un- in Middle English, which was forced out by non- in Early New English. For example, un-time unseasonable, inopportune (non-seasonal). LSG $\mathrm{N}_{6}$ was combined with the prefix $d e$ - in Middle English, which was forced out by dis- and $e x$ - in Early New English. For example, dis-plume - n.e. to strip of plumes, moult (without action).

LSG $\mathrm{N}_{9}$ was combined with the prefix dis- in Middle English and increased its inventory with such prefixes as: be- and in- in Early New English. For example, dis-helm - m.e. to deprive or disarm of one's helmet (deprive a helmet).

The modern system of prefixes of LSG $\mathrm{N}_{10}$ of the onomasiological category of Negation was formed in Middle English with the help of the prefixes dis- and in-which, without any changes, still participate in the formation of this onomasiological category nowadays. For example, in-digestion - n.e. want of digestion.

LSG $\mathrm{N}_{18}$ was combined with the prefix $u n$ - in Middle English, which in Early New English was forced out by two prefixes: $a$ - and in-. For example, $\boldsymbol{a}$ catastasis - n.e. an unsettling (unstable state). 
LSG $\mathrm{N}_{1}, \mathrm{~N}_{2}, \mathrm{~N}_{5}, \mathrm{~N}_{8}, \mathrm{~N}_{15}$ have been present since Early New English. So, LSG $\mathrm{N}_{1}$ was combined with prefixes: dis-, in-, under-; $\mathrm{N}_{2}$ with be-, in-; $\mathrm{N}_{5}$ with dis-, in-; $\mathrm{N}_{8}$ with dis-, under-; $\mathrm{N}_{15}$ with dis-, ex-, under. For example, dis-room e.n.e. to displace; be-flake - n.e. to take off an external layer, skin in thin flakes; dis-pearl-e.n.e. to deprive of pearls.

A small number of verbal base LSG which participate in the formation of the onomasiological category of Negation cannot single out the nucleus, the main corpus and periphery of this category. Structural and semantic models of these LSG were not highly productive. There is an exception to the model $\mathrm{Pr}+$ $\mathrm{V}_{8}>\mathrm{V}$ which was productive only in Old English and Middle English. Another productive model was $\mathrm{Pr}+\mathrm{V}_{6}>\mathrm{V}$ in Middle English. Other models such as $\mathrm{Pr}+$ $\mathrm{V}_{9}>\mathrm{V}, \operatorname{Pr}+\mathrm{V}_{2}>\mathrm{V}, \operatorname{Pr}+\mathrm{V}_{7}>\mathrm{V}, \operatorname{Pr}+\mathrm{V}_{4}>\mathrm{V}$ were non-productive.

LSG $\mathrm{V}_{8}$ took an active part in the formation of the onomasiological category of Negation in the first two periods. In Old English, this group was combined with the prefixes: be-, for-, to-, in Middle English its inventory received mis-, but in this period $L S G \mathrm{~V}_{8}$ also stopped forming verbal derivatives with the prefix for-. In Early New English, its word-building potential was expanded with the prefix $e x$ - while authentic prefixes be-, to-, mis- went out of use. Nowadays LSG $\mathrm{V}_{8}$ is combined only with the prefix $e x$-. For example, $\boldsymbol{b} \boldsymbol{e}$ dalan (divide) - o.e. to deprive, rob, strip.

LSG $\mathrm{V}_{9}$ was active only during the first two periods; during the next two phases its verbal derivatives were not recorded. In Old English it was combined with the prefixes be-and for-, in Middle English it additionally combined with mis-, but the prefix for- went out of use. In Early New English, LSG $\mathrm{V}_{9}$ stopped to form verbal derivatives involving prefixes $b e$ - and mis-. For example, $\boldsymbol{b} \boldsymbol{e}$ tellan -o.e. to clear a person of a charge.

In Old English LSG $\mathrm{V}_{2}$ combined with the prefixes be-, for-, to-, in Middle English its inventory grew at the expense of the prefix mis-. However, in Middle English, the prefix for-went out of use, and in Early New English the prefixes mis- and to- stopped forming derivatives. For example, un-lay-m.e. not to lay.

LSG $\mathrm{V}_{4}, \mathrm{~V}_{7}, \mathrm{~V}_{6}$ were active only during Middle English. Thus LSG $\mathrm{V}_{4}$ combined with prefixes at-, mis-, to-; LSG $\mathrm{V}_{7}$ and $\mathrm{V}_{6}$ formed derivatives with the prefix mis-. For example, a-schamien - m.e. to make ashamed, put to shame; over-write - e.n.e. to cover over with writing, for-dwinan (blossom) - o.e. to fade away, dwindle away.

\section{Conclusions}

During the four stages in the history of English the combinatory dynamics of LSG reveals certain patterns. The realisation of the LSG of the onomasiological category of Negation has increased, which proves the fact that the substantive 
derivative bases were not active during the early stages of its formation. The main corpus and nucleus of the onomasiological category of Negation underwent expansion due to increased productivity of their components, and the periphery developed due to the appearance of new LSG. The onomasiological category of Negation has been represented by 2 out of 9 LSG of singled out verbal derivative bases. They are LSG denoting "verbs of motion", and "verbs of physical activity". And the LSG of derivative bases denoting "verbs of communication", "verbs of feelings", "verbs of location", "verbs of intellectual activity" also acquired a reference to negation in certain periods in the history of English.

The onomasiological category of Negation was formed by the following nucleus LSG of substantive derivative bases: $\mathrm{N}_{11}, \mathrm{~N}_{12}, \mathrm{~N}_{16}$, and the wordbuilding potential has expanded meanwhile with $\mathrm{N}_{7}, \mathrm{~N}_{13}, \mathrm{~N}_{14}, \mathrm{~N}_{17}, \mathrm{~N}_{19}$. LSG with insignificant or no word-building potential are: $\mathrm{N}_{1}, \mathrm{~N}_{2}, \mathrm{~N}_{3}, \mathrm{~N}_{4}, \mathrm{~N}_{5}, \mathrm{~N}_{6}, \mathrm{~N}_{8}$, $\mathrm{N}_{9}, \mathrm{~N}_{10}, \mathrm{~N}_{15}, \mathrm{~N}_{18}$. As to the LSG of the verbal derivative bases of this category, they are characterized by small or no word-building potential. Besides, in each period of the English language $\mathrm{LSG} \mathrm{V}_{8}, \mathrm{~V}_{9}, \mathrm{~V}_{2}, \mathrm{~V}_{6}, \mathrm{~V}_{7}, \mathrm{~V}_{4}$ were combined with various prefixes. We can conclude that the onomasiological category of Negation is basically the substantive, but not the verbal category. The prospect for our further study is to investigate the role of adjective and adverbial derivatives in the formation of the prefixal and onomasiological category of Negation.

\section{Works Cited}

Kizyukevich, A.A., Structural, semantic and onomasiological aspects of transposition as a special way of nomination of reality phenomena, Moscow, 1989.

Kubryakova, E.S., Parts of speech in onomasiological interpretation, Moscow, LKI, 2008.

Lopatin, V.V., "Word formation as an object of grammatical description (concepts and methods)" in Grammar description of Slavic languages, Moscow, 1974.

Polyuzhyn, M.M., Diachronic and semantic aspects of prefixal word-formation in English, Moscow, 1992.

Selivanova, O. O., Modern Linguistics: Directions and Problems, Poltava, Environment, 2008.

Ulukhanov, I.S., "Structure of lexical meanings of motivated words" in Questions of Word Formation and Phrase Formation in Germanic Languages, Issue 164, 1980.

Zemskaya, E.A., Language as Activity: Morpheme. Word. Speech, Moscow, Languages of Slavic Culture, 2004. 


\section{BIONOTE}

Olga Migorian is Associate Professor in the Department of English of the Foreign Language Faculty, Yuriy Fedkovych Chernivtsi National University, Ukraine. My research interests are English Lexicology, English History, Onomasiology, I specialize in English and Academic English. I have published in various journals and in various collections of essays. Among my latest articles are "The Derivative Aspect of the Formation of the Prefixal-Onomasiological Category of Rank" in Papers and Commentaries Vol.VI, Cambridge University Press, 2016, "Diachronic Peculiarities of the Compatibility of Lexico-Semantic Groups of Adjectival Bases and Prefixes within the Onomasiological Categories" in Scientific Bulletin of Chernivtsi University No. 784/2017, "Derivative Peculiarities of Formation of Prefixal and Onomasiological Category of Phase with the Help of Noun Derivatives" in Scientific Bulletin of the International Humanities University No. 31/2018 and "The notional characteristics of the formation of the prefixal and onomasiological category of Partitiveness" in International Scientific Journal for Smart Innovations Issue № $1 / 2019$.

Email: viznukf@gmail.com 
